\title{
Open-Source Joystick Manipulandum for Decision- Making, Reaching, and Motor Control Studies in Mice
}

\author{
Parley P. Belsey, ${ }^{1}$ Mark A. Nicholas, ${ }^{1}$ and Eric A. Yttri ${ }^{1,2}$
}

https://doi.org/10.1523/ENEURO.0523-19.2020

${ }^{1}$ Department of Biological Sciences, Carnegie Mellon University, Pittsburgh, PA 15213 and ${ }^{2}$ Carnegie Mellon Neuroscience Institute, Carnegie Mellon University, Pittsburgh, PA 15213

\section{Visual Abstract}

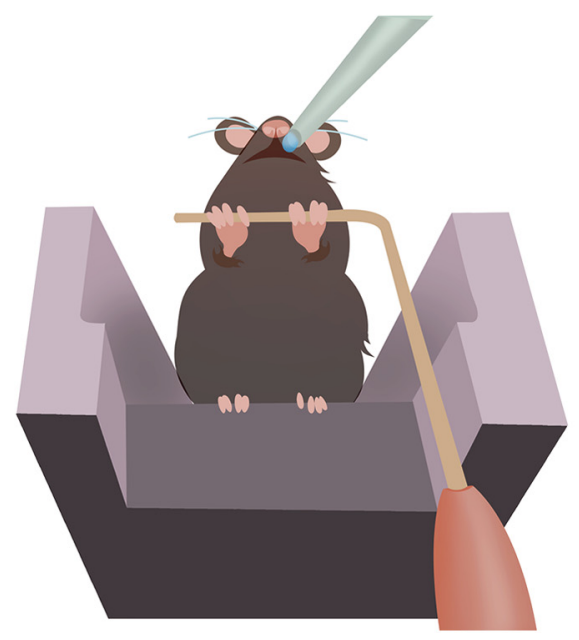

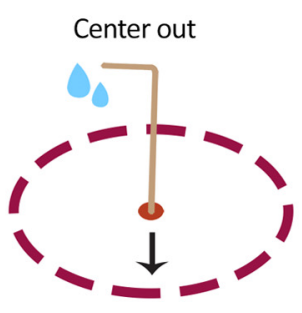

Cued reaction time

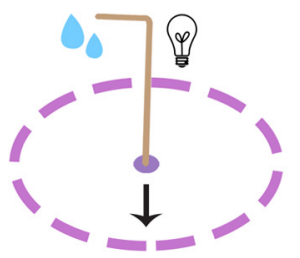

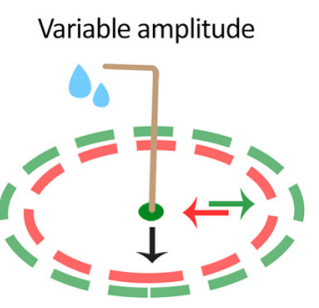

Directional two-armed bandit

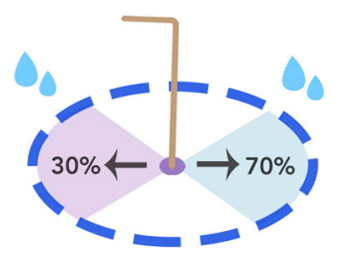

To make full use of optogenetic and molecular techniques in the study of motor control, rich behavioral paradigms for rodents must rise to the same level of sophistication and applicability. We describe the layout, construction, use and analysis of data from joystick-based reaching in a head-fixed mouse. The step-by-step guide is designed for both experienced rodent motor labs and new groups looking to enter into this research space. Using this platform, mice learn to consistently perform large, easily-quantified reaches, including during a two-armed bandit probabilistic learning task. The metrics of performance (reach trajectory, amplitude, speed, duration, and inter-reach interval) can be used to quantify behavior or administer stimulation in closed loop with behavior. We provide a highly customizable, low cost and reproducible open-source behavior

\section{Significance Statement}

We are realizing that the behavioral repertoire of mice is much richer than previously thought, including motor control and decision-making using reaches. Modern neuroscience is now capturing this richness, paired with new genetic tools, to understand fundamental neuroscience principles. Here, we provide an illustrated build guide, code, multiple use scenarios, and analytic tools to a low-cost, highly customizable mouse joystick. This tool will enable improved throughput, accessibility, and experimental design (e.g., spatiotemporal reach trajectories over lever presses) for labs wishing to study a range of reach-based experiments. 
training platform for studying motor control, decision-making, and reaching reaction time. The development of this software and hardware platform enables behavioral work to complement recent advances in rodents, while remaining accessible to smaller institutions and labs, thus providing a high-throughput method to study unexplored features of action selection, motivation, and value-based decisions.

Key words: decision-making; high-throughput; mouse; operant; reaching; rodent

\section{Introduction}

Reaching is a well-studied neuroscience paradigm, across several species (Fromm and Evarts, 1981; Churchland et al., 2012; Dean et al., 2012; Cherian et al., 2013; Yttri et al., 2013; Mathis et al., 2017). This goal-oriented movement is highly quantifiable, reproducible, and unitary, unlike other tasks common to rodents that require several actions, such as reorientation followed by locomotion across a cage (Tai et al., 2012; Lak et al., 2014). Despite its simplicity, the action provides rich spatiotemporal dynamics (Bollu et al., 2019) that do not exist in other paradigms such as lever presses. The quantification of such richness is made trivial through the use of joysticks. Joystick manipulandums have been used for decades in both human and nonhuman primates studies of reaching (Thoroughman and Shadmehr, 1999; Maeda et al., 2018), and more recently in rats (Slutzky et al., 2010). Because joysticks provide realtime readout of the $x$ and $y$ trajectory (and therefore position and speed information), joysticks enable the study of ongoing correlated neural activity (Paninski et al., 2004; Panigrahi et al., 2015) or stimulation in closed loop triggered off a specific spatiotemporal feature of movement (Yttri and Dudman, 2016). This quality presents a significant advantage over impressive, but post hoc, computer vision techniques (Guo et al., 2015; Mathis et al., 2018) that cannot yet offer real-time reporting of reach position.

The use of mice to study the spatiotemporal dynamics of behavior has increased considerably in recent years (Harvey et al., 2009; Cohen et al., 2015; Guo et al., 2015;

Received December 12, 2019; accepted January 31, 2020; First published February 24, 2020.

The authors declare no competing financial interests.

Author contributions: P.P.B., M.A.N., and E.A.Y. designed research; P.P.B. and M.A.N. performed research and analyzed data; M.A.N. wrote and developed acquisition and analysis software; P.P.B. and E.A.Y. wrote the paper.

This work was supported by the Whitehall Foundation, the Carnegie Mellon University Summer Undergraduate Research Fellowship, and the Charles E. Kaufman Foundation, a supporting organization of The Pittsburgh Foundation. P.P.B. was supported by donors to the Undergraduate Research OfficeSummer Undergraduate Research Fellowship at Carnegie Mellon University.

Acknowledgements: We thank Alex Hodge and especially Joshua Dudman and his group at Janelia Research Campus for their contributions to the development of this project. We also thank Andrew Buzza for his influence on the animal restraint design as well as Ryan Bates and the Carnegie Mellon Tech Spark team for manufacturing and technical support.

Correspondence should be addressed to Eric A. Yttri at eyttri@ andrew.cmu.edu.

https://doi.org/10.1523/ENEURO.0523-19.2020

Copyright $@ 2020$ Belsey et al.

This is an open-access article distributed under the terms of the Creative Commons Attribution 4.0 International license, which permits unrestricted use, distribution and reproduction in any medium provided that the original work is properly attributed.
Klaus et al., 2017). Through the application of genetic tools, unprecedented avenues of discovery have been made possible in the study of the brain, including those of decision-making and motor control. While considerable work using "center-out" reaching tasks have been done in human and non-human primates, performing similar studies in rodents provides many advantages. Beyond optogenetic manipulations, studying reaching movements in mice also supports high-throughput methods that rapidly accelerate our understanding of the underlying brain circuits. As a side-effect of this approach, researchers can better capture behavioral and animal variance (rather than the typical "two monkey" rule), while also greatly reducing monetary barriers to entry that may prohibit smaller labs and institutions from participating in behavioral work (Brunton et al., 2013; Guo et al., 2015). In order to take advantage of these features, however, expansion of rigorous mouse behavioral paradigms must occur (Fetsch, 2016). Here, an inexpensive, open source 2D joystick platform, including hardware, software, online and offline analysis code is described (https://github.com/YttriLab/Joystick). This joystick can be put into practice quickly and provides precise, millisecond resolution readouts of limb position in real-time. We describe its usage for a basic center-out task, a cued reaction time version of that task, and a bi-directional "two-armed bandit" probabilistic learning task.

\section{Materials and Methods}

\section{Behavior rig hardware}

Figure $1 A$ shows a behavior rig (9" $\mathrm{H} \times 4$ " $\mathrm{W} \times 12$ " $\mathrm{D})$, consisting of three main components: a removable headfixation unit, joystick, and positionable sipping tube, all secured to an optical breadboard for easy arrangement. This setup works with a number of mouse head-fixation solutions; pictured in Figure $1 A$ is the RIVETS system (Osborne and Dudman, 2014) and pictured in Figure $1 B$ are custom built head-fixation units. The RIVETS system designs are available for download on the Dudman website on the Designs page, where the lab describes success using $3 \mathrm{D}$ printed and machined versions of the RIVETS system. The design for the custom platform unit is available to download on the Yttri Lab GitHub (https://github.com/ YttriLab/Joystick/tree/master/Mouse\%20Shuttle\%20Parts). While the parts and plans for the shuttle-holding platform provide several advantages (solid construction, easy changing of height, automatic locking into place of the animal shuttle), the joystick platform should be amenable to most any head-fixation system. This animal shuttle is held in position with a precise yet easily removable knobbed magnetic base (Thorlabs, part KB2X2). The application of this piece in particular is a great function of the build, as it 
A
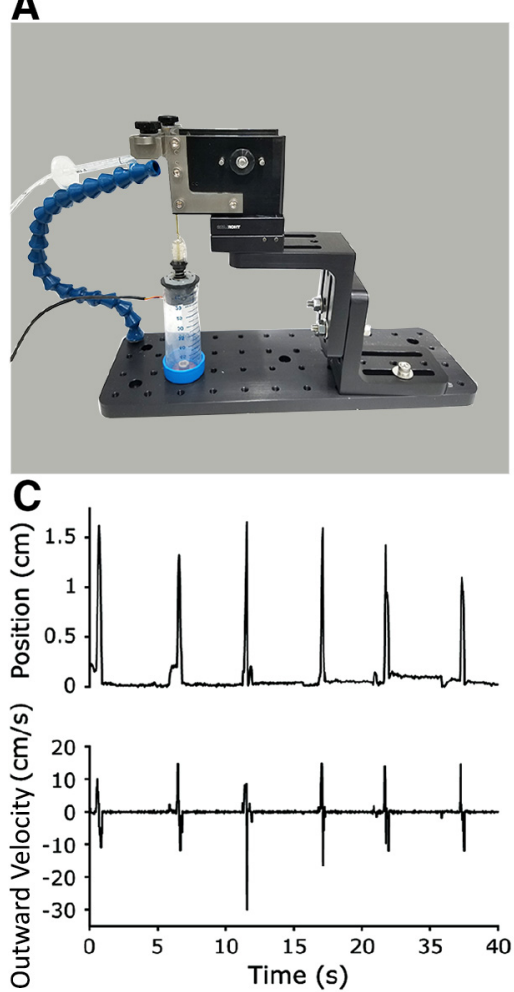

B

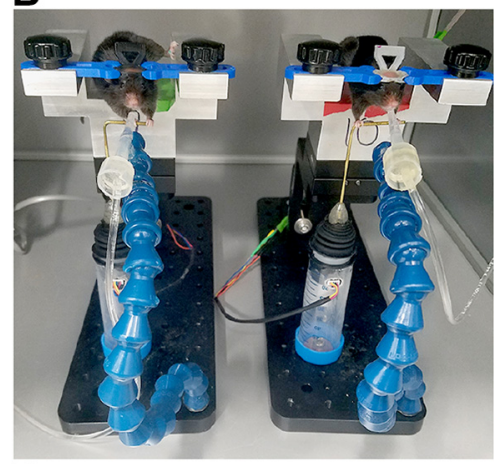

D

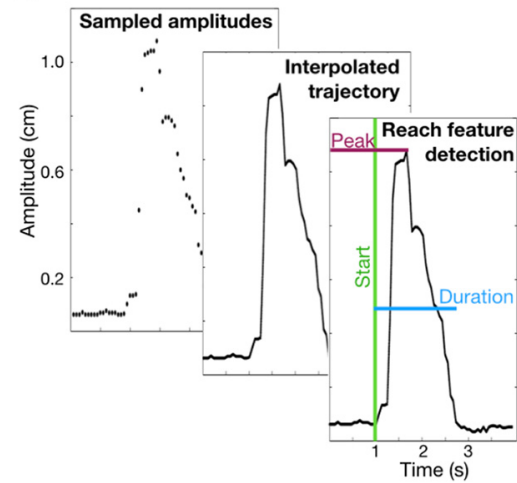

Figure 1. Reaching setup and performance. $\boldsymbol{A}$, Training platform hardware is adjustable and customizable to task demands. $\boldsymbol{B}$, Mice can perform reaching tasks in behavioral boxes and with minimal space usage. Reward water is dispensed through a solenoid circuit based on task parameters and mouse performance, monitored online with an Arduino. Joystick is positioned $\sim 2 \mathrm{~cm}$ directly below mouse's eyes. $\boldsymbol{C}$, Amplitude (top) and outward velocity (bottom) traces from a trained mouse performing the basic center-out task. $\boldsymbol{D}$, Data processing flow for a sample reach. Measured joystick positions sampled over time are assembled into reach trajectories offline. The described software package identifies the reach start time and various features of each reach, including peak amplitude and duration.

enables modularity and easy, never-fail docking of multiple head-fixed rigs.

The sipper tube is attached to Loc-Line tubing, allowing for easy positioning adjustments across animals. The water line and corresponding solenoid can be flushed using a $10 \%$ bleach solution followed by water for cleaning, with the Flush sketch available on the Yttri Lab GitHub. A spring-loaded, miniature hall effect joystick (Ruffy Controls, TS1) was chosen because it can relay the position of reaches with submillisecond delay and removes the potential for biases along the $x$ - and $y$-axes that may be encountered with traditional two-axis potentiometer joysticks. The joystick is fixed at a height and distance that a head-fixed mouse can comfortably grasp the attached bar with both paws $(\sim 2 \mathrm{~cm}$ below the mouse's eye). The joystick can be mounted in a number of ways, including fitting into a $50 \mathrm{ml}$ Falcon tube that is then screwed onto the breadboard, as shown in Figure $1 A, B$. This solution provides a surprisingly solid pedestal comparable to direct mounting to a more expensive, solid metal stand. Figure $1 B$ demonstrates the rig's small size and ease of assembly, which enables a lab to quickly set up dozens of rigs in a limited space.

While relatively inexpensive (Table 1), additional options to substantially reduce cost include a less substantial, permanent animal pedestal (could be directly bolted to surface, a savings of $>\$ 200$ ) or using a two-axis potentiometer joystick $(\sim \$ 5)$ in place of Hall effect joysticks $(\sim \$ 75)$. The latter provides uniform resistance in every direction, instead of having two axes along which there is less resistance. These tracks have the potential to skew the 2D trajectory of the reach, although this may not be of consequence for some experimental questions. The moving parts of the potentiometers are also more likely to break down over time. If more delicate reach kinematics are of interest, we have observed that the Ruffy TS1 joystick resistance can be reduced by cutting the spring by up to 1.5 coils without risking the joystick's ability to return to center. With one coil removed, it takes only $0.18 \mathrm{~N}$ to displace the joystick $1 \mathrm{~cm}$. Other solutions include using a near zero resistance joystick designed for rodents, particularly that described in Bollu et al. (2019).

The data acquisition hardware is comprised of an Arduino, solenoid circuit, microSD card reader, and LCD readout. Although not necessary for task execution, the LCD screen provides valuable information on animal performance and feedback during debugging. The uploaded Arduino sketch determines if a correct reach has been performed based on joystick position and timing and delivers the predetermined water reward. Real-time task 
Table 1: Parts list for joystick build

\begin{tabular}{|c|c|c|c|}
\hline \multicolumn{4}{|c|}{ Materials order form } \\
\hline \multicolumn{4}{|l|}{ Base Lab Tools } \\
\hline $\begin{array}{l}1 / 4-20 \text { stainless-steel } \\
\text { screw kit }\end{array}$ & SKT25 & $\begin{array}{l}\text { Screw kit including } 1 / 4-20 \text { cap screw, set } \\
\text { screws, nuts, washers }\end{array}$ & $\$ 49.00$ \\
\hline Optical breadboard & SAB0412-D & $\begin{array}{l}4 " \times 12^{\prime \prime} \times 1 / 2 " \text { solid aluminum optical } \\
\text { breadboard, black anodized }\end{array}$ & $\$ 65.00$ \\
\hline $\begin{array}{l}\text { Right angle mounting } \\
\text { bracket }\end{array}$ & ABS002 & $\begin{array}{l}2 " \text { right angle mounting bracket, narrow } \\
\text { slotted (1) }\end{array}$ & $\$ 39.00$ \\
\hline $\begin{array}{l}0.34 " \text { ID, 0.875" OD } \\
\text { washer }\end{array}$ & 93490A030 & $\begin{array}{l}\text { Bronze washer for } 5 / 16 " \text { screw size, } \\
0.34 " \text { ID, 0.875" OD (pack of 10) }\end{array}$ & $\$ 5.70$ \\
\hline $\begin{array}{l}\text { 1/16" ID, 1/8" OD } \\
\text { tubing }\end{array}$ & $6516 \mathrm{~T} 11$ & $\begin{array}{l}\text { Tygon PVC clear tubing 1/16" ID, 1/8" OD, } \\
25 \mathrm{ft} \text { length }\end{array}$ & $\$ 5.75$ \\
\hline 1/16" brass wire & $8859 K 511$ & $\begin{array}{l}\text { Ultra-formable } 260 \text { brass } 1 \text { foot long } \\
\text { Rod, 1/16" diameter (pack of } 3 \text { ) }\end{array}$ & $\$ 2.03$ \\
\hline \multicolumn{4}{|c|}{ 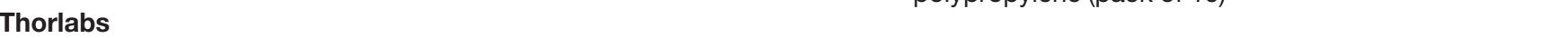 } \\
\hline Item: & Catalog number: & Description: & Price: \\
\hline Kinematic base & $\mathrm{KB} 2 \times 2$ & $\begin{array}{l}2 " \times 2 \text { " kinematic base, top and } \\
\text { bottom plates, } 1 / 4 "-20 \text { mounting }\end{array}$ & $\$ 83.39$ \\
\hline \multicolumn{4}{|l|}{ Ruffy Controls } \\
\hline Item: & Catalog number: & Description: & Price: \\
\hline $\begin{array}{l}\text { Miniature } 2 \text { axis hall } \\
\text { effect joystick }\end{array}$ & TS1-1-R-R-1-BK & $\begin{array}{l}\text { TS1, stepped cap, round limiter, rear mount, } \\
0-5 \mathrm{v} \text {, black }\end{array}$ & $\$ 75.00$ \\
\hline \multicolumn{4}{|l|}{ Items from other retailors } \\
\hline Item: & Catalog Number: & Website: & Price: \\
\hline $\begin{array}{l}\text { 3-Port Ported: Conventional } \\
\text { Solenoid }\end{array}$ & LHDA1233115H & $\begin{array}{l}\text { https://www.theleeco.com/products/electro- } \\
\text { fluidic-systems/solenoid-valves/control- } \\
\text { valves/lhd-series/3-port/ported/ }\end{array}$ & $\$ 74.00$ \\
\hline $\begin{array}{l}\text { Battery clip } \\
\text { connector }\end{array}$ & $\begin{array}{l}\text { 9-V clip on type battery snap } \\
\text { connector lead wire plastic } \\
\text { head, } 10 \text { pieces }\end{array}$ & $\begin{array}{l}\text { https://www.amazon.com/Battery- } \\
\text { Connector-Plastic-Atomic-Market/dp/ } \\
\text { B00IDHZ5FM }\end{array}$ & $\$ 6.99$ \\
\hline $1 \mathrm{~K}$ diodes & $\begin{array}{l}\text { 1N5408 rectifier diode } 3 \mathrm{~A} \\
1000 \mathrm{~V}\end{array}$ & $\begin{array}{l}\text { https://www.amazon.com/Parts-Express- } \\
\text { 1N5408-Rectifier-Diode/dp/B0009XSN02 }\end{array}$ & $\$ 6.91$ \\
\hline $\begin{array}{l}\text { Electrical } \\
\text { breadboard }\end{array}$ & $\begin{array}{l}\text { BB400 solderless plug-in } \\
\text { breadboard, } 400 \text { tie-points, } \\
4 \text { power rails, } 3.3 \times 2.2 \times \\
0.3^{\text {" }}(84 \times 55 \times 9 \mathrm{~mm})\end{array}$ & $\begin{array}{l}\text { https://www.amazon.com/BB400- } \\
\text { Solderless-Plug-BreadBoard-tiepoints/dp/ } \\
\text { B0040Z1ERO }\end{array}$ & $\$ 5.90$ \\
\hline $\begin{array}{l}\text { Elegoo } \\
\text { board }\end{array}$ & $\begin{array}{l}\text { Elegoo EL-CB-001 UNO R3 } \\
\text { board ATmega328P } \\
\text { ATMEGA16U2 with USB } \\
\text { cable for Arduino }\end{array}$ & $\begin{array}{l}\text { https://www.amazon.com/Elegoo-EL-CB- } \\
\text { 001-ATmega328PATMEGA16U2-Arduino/ } \\
\text { dp/B01EWOE0UU }\end{array}$ & $\$ 10.86$ \\
\hline $\begin{array}{l}\text { Heat shrink } \\
\text { tubing, } 1 / 8 "\end{array}$ & $\begin{array}{l}\text { WindyNation 1/8" } 20 \text { Feet } \\
\text { Black 3:1 Dual Wall } \\
\text { Adhesive Glue Lined } \\
\text { Marine Grade Heat Shrink } \\
\text { Tube Tubing }\end{array}$ & $\begin{array}{l}\text { https://www.amazon.com/WindyNation-20- } \\
\text { Feet-Black-Adhesive/dp/B07LB8Z7HZ/ } \\
\text { ref=sr_1_4?keywords=1\%2F8+heat } \\
\text { +shrink+tubing\&qid=1582813388\&s= } \\
\text { industrial\&sr=1-4 }\end{array}$ & $\$ 16.99$ \\
\hline Jumper cables & $\begin{array}{l}40 \text { pin male to female, } 40 \text { pin } \\
\text { male to male, } 40 \text { pin female } \\
\text { to female breadboard } \\
\text { jumper wire ribbon Dupont } \\
\text { cables kit, } 120 \text { pieces } \\
\text { (Continued) }\end{array}$ & $\begin{array}{l}\text { https://www.amazon.com/COMeap-120pcs- } \\
\text { Female-Breadboard-Jumper/dp/ } \\
\text { B01MUOIMFF/ref=sr_1_4?s=industrial\&ie= } \\
\text { UTF8\&qid=1538699670\&sr=1-4\& } \\
\text { keywords=male+male+jumper+cables }\end{array}$ & $\$ 7.99$ \\
\hline
\end{tabular}


Table 1: Continued

\begin{tabular}{|c|c|c|c|}
\hline \multicolumn{4}{|c|}{ Materials order form } \\
\hline Item: & Description: & Website: & Price: \\
\hline LCD screen & $\begin{array}{l}\text { LGDe home IIC/I2C/TWI LCD } \\
160216 \times 2 \text { serial interface } \\
\text { adapter module blue back- } \\
\text { light for Arduino UNO R3 } \\
\text { MEGA2560 ( } 2 \text { pack) }\end{array}$ & $\begin{array}{l}\text { https://www.amazon.com/LGDehome- } \\
\text { Interface-Adapter-Backlight-MEGA2560/ } \\
\text { dp/B0711WLVP9 }\end{array}$ & $\$ 9.59$ \\
\hline MicroSD card & $\begin{array}{l}\text { MicroSD card 32GB, } \\
\text { AUAMOZ microSDHC class } \\
10 \text { UHS-I high-speed mem- } \\
\text { ory card for phone, tablet, } \\
\text { and PCs, with adapter ( } 2 \\
\text { pack) }\end{array}$ & $\begin{array}{l}\text { https://www.amazon.com/gp/product/ } \\
\text { B07DGHCFSM/ref=oh_aui_search_asin_ } \\
\text { title?ie=UTF8\&psc=1 }\end{array}$ & $\$ 16.12$ \\
\hline $\begin{array}{l}\text { MicroSD card reader } \\
\text { for Arduino }\end{array}$ & $\begin{array}{l}\text { SenMod } 5 \text { PCS microSD card } \\
\text { microSDHC mini TF card } \\
\text { adapter reader module for } \\
\text { Arduino }\end{array}$ & $\begin{array}{l}\text { https://www.amazon.com/gp/product/ } \\
\text { B01JYNEX56/ref=ppx_yo_dt_b_asin_title_ } \\
\text { o00_o00_s00?ie=UTF8\&psc=1 }\end{array}$ & $\$ 8.29$ \\
\hline $\begin{array}{l}\text { RJ11 } \\
\text { Telephone } \\
\text { cable }\end{array}$ & $\begin{array}{l}\text { C2G/cables to Go } 02970 \\
\text { RJ11 modular telephone } \\
\text { cable, silver ( } 7 \text { feet, } 2.13 \mathrm{~m})\end{array}$ & $\begin{array}{l}\text { https://www.amazon.com/C2GCables- } \\
\text { Modular-Telephone-Silver/dp/ } \\
\text { B00006HSK6 }\end{array}$ & $\$ 3.47$ \\
\hline $\begin{array}{l}60-\mathrm{V} \\
\text { transistors }\end{array}$ & $\begin{array}{l}\text { Major brands TIP120. transis- } \\
\text { tor, Darlington, NPN, } 60 \text { V, } \\
5 \text { A, 3-pin, 3+ Tab, TO- } \\
\text { 220, } \\
\text { AmpB, rail, pack of } 15\end{array}$ & $\begin{array}{l}\text { https://www.amazon.com/Major-Brands- } \\
\text { TIP120-Transistor-Darlington/dp/ } \\
\text { B00B888622/ref=Ip_306910011_1_7?s= } \\
\text { industrial\&ie=UTF8\&qid=1538700353\&sr= } \\
\text { 1-7 }\end{array}$ & $\$ 5.99$ \\
\hline
\end{tabular}

Parts, prices, and vendors are included for the joystick build. Approximate cost of one setup: $\$ 440$. PDF of step by step build instructions for creating the joystick training platform are available in Extended Data 1.

information, such as number of reaches, time, number of punishments, and moving average of last five RTs are displayed on the LCD screen, and session data are written to a microSD card for saving and later analysis. This setup can also be used to deliver stimulation in closed loop with behavioral performance aspects (e.g., reach speed). Full build and part ordering instructions can be found at https:// github.com/YttriLab/Joystick and (Extended Data 2).

Two methods of data acquisition were developed to satisfy a range experimental demands. Code written in Processing software displays a real-time visual of joystick position and task parameters while saving data to a .csv file. In addition to writing to a local machine, the data file can be written to a microSD card. Sending data wirelessly over Wi-Fi may also be performed. Other data relay methods, including solutions from LabJack or the Open Ephys acquisition system may be used with this joystick/Arduino build as well.

\section{Behavioral task software}

Reach position is calculated through the Hall effect sensor in the joystick, which measures the magnitude of the magnetic field generated by magnet attached to the joystick, and output a proportionate voltage to the Arduino board (Stewart, 2017). From xy position output, the Arduino sketch calculates the Euclidean distance between "baseline" position and current joystick position. To complete a basic trial, mice perform bimanual reaches at a self-directed pace (Fig. 1C). The joystick setup can also be adapted to perform unimanual (or double unimanual) reaches. When the reach position surpasses the amplitude threshold, sweetened water is delivered after a 1-s delay. This delay is in place to help dissociate movement and reward representations in the brain. A new trial begins after a fixed, 3-s inter-trial interval (ITI), in order to obtain discrete movements. In our reaction time experiments, two adult C57/bl6 mice were used in each condition (one male, one female).

We describe the basic flow of data processing in Figure 1D. Code for running these tasks and offline data analysis used to quantify reach performance, including trajectory, amplitude, peak speed, duration, and inter-reach interval has been produced and is available at https://github.com/ YttriLab/Joystick. Here, we also offer offline analysis code (Online and Offline Joystick Code available in Extended Data 2), although this study's major contribution is in the form of the physical joystick design, construction, and online task code. In our offline analysis, reach detection is based on threshold crossing, and works forward and backwards in time from a minimal reach amplitude threshold crossing to determine exact reach initiation and termination times. In doing so, the user is able to select for only full reaches and ignore small "blips" due to postural adjustment, grooming, or other non-task related behavior.

\section{Results}

Adult mice can be easily, and automatedly, trained to make large, reproducible reaches covering upwards of 2 $\mathrm{cm}$. Figure $1 \mathrm{C}$ provides a demonstration of the online readout while the tool is in use. Video of mouse performance and online reach-position readout, including task state, threshold, time, and number of trials performed 


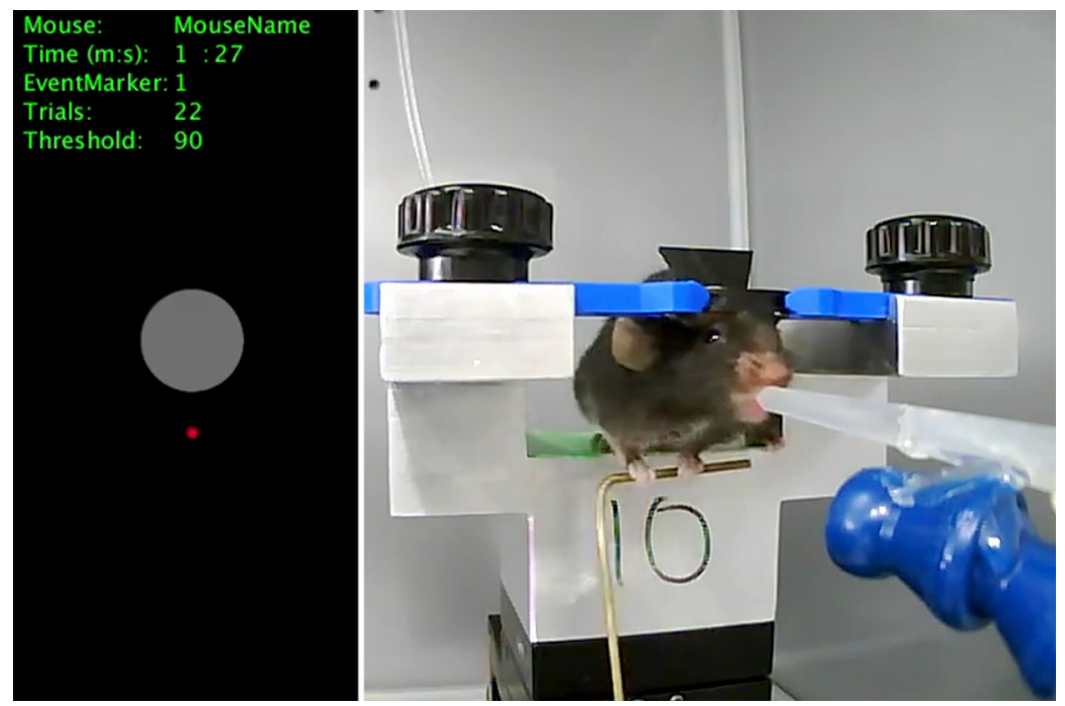

Movie 1. Video of mouse performance and online reach-position readout, including task state, threshold, time, and number of trials performed. [View online]

available in Movie 1. The joystick setup can capture fine variations in performance metrics including trajectory, outward velocity, amplitude, and duration (Fig. 2A-C).

For training, in addition to water control, we recommend the use of $3 \mathrm{mM}$ acesulfame potassium, an artificial sweetener in the reward water. Artificial sweeteners are not readily digested by microbes, and thus require fewer line cleanings. This also eliminates potential concerns about the caloric quantity of the reward, though note that artificial sweeteners are perceived differently in the brain than sucrose (Kaskan et al. 2019). Prior to surgical implantation of the head cap, mice are exposed to experimenter handling. Two days after surgery, mice were head-fixed in the shuttle for increasing periods of time (5-45 min) and hand watered while head-fixed over the subsequent $3 \mathrm{~d}$. Mice are placed on water control one to $3 \mathrm{~d}$ prior to the first day of experimentation and kept on water control for the duration of the experiment. Training is comprised of a two-week period where mice are fixed in the behavioral rig, in a darkened behavior box (18" $\mathrm{H} \times 20$ " $\mathrm{W} \times 22$ " D) for $30 \mathrm{~min}$ at a time (Fig. 1B). In the first $3 \mathrm{~d}$, mice perform two, 30-min sessions per day (morning and afternoon) to increase the rate of learning of the reaching behavior, while single 30-min session are performed for the rest of training and experimentation. Over the course of the training period, threshold to receive water increases from $0.1 \mathrm{~cm}$, where almost any movement of the joystick results in water reward, to $0.9 \mathrm{~cm}$, with naive mice reaching expert level (defined as $>100$ successful reaches/session with a reward threshold of $>0.9 \mathrm{~cm}$ from center) in two to three weeks. After the initial joystick movement-water connection is established (typically one to six sessions), set threshold is increased gradually (no more than $1 \mathrm{~mm}$ / d), as strength and endurance to complete the task needs to be built up. Delay to reward is increased gradually $(50 \mathrm{~ms} / \mathrm{d})$ along with threshold from $500 \mathrm{~ms}$ to $1 \mathrm{~s}$ as mice reached $0.9-\mathrm{cm}$ reach proficiency. As shown in Figure $2 A-$ $C$, reach dynamics are refined after initial task learning has elapsed. All animal procedures were performed in
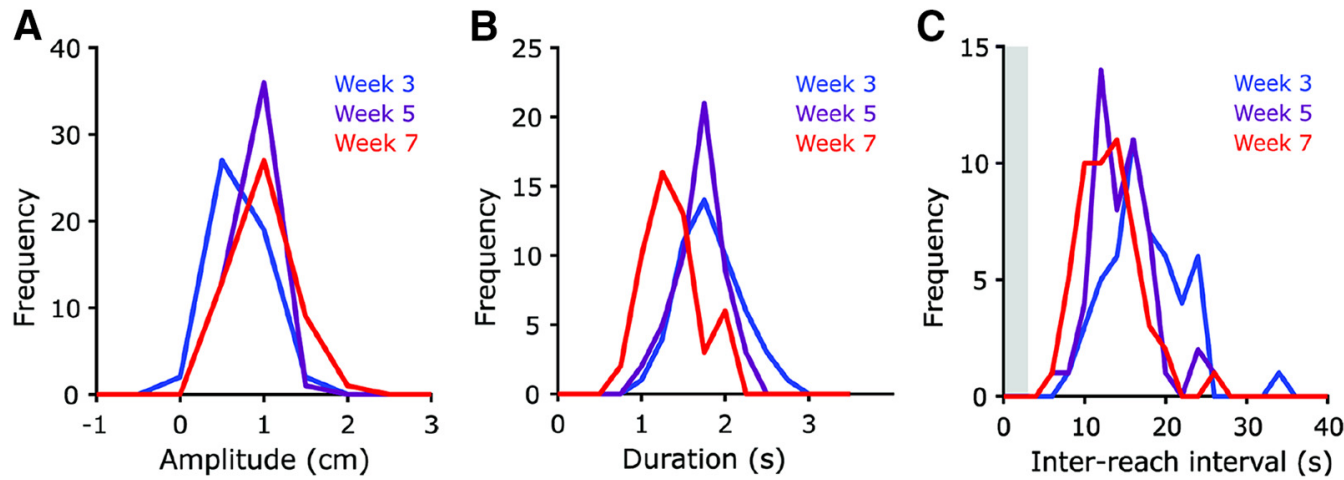

Figure 2. A, Peak amplitude, $\boldsymbol{B}$, reach duration, $\boldsymbol{C}$, inter-reach interval (IRI) for the first 50 trials performed in each session during weeks 3, 5, and 7. Inter-trial interval, shown in light grey, is set at 3 seconds in the basic task, and is included in IRI plot shown above. 
A

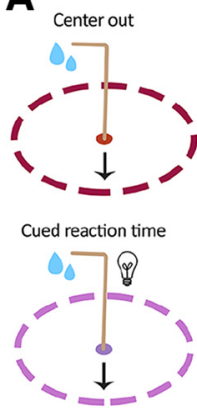

B
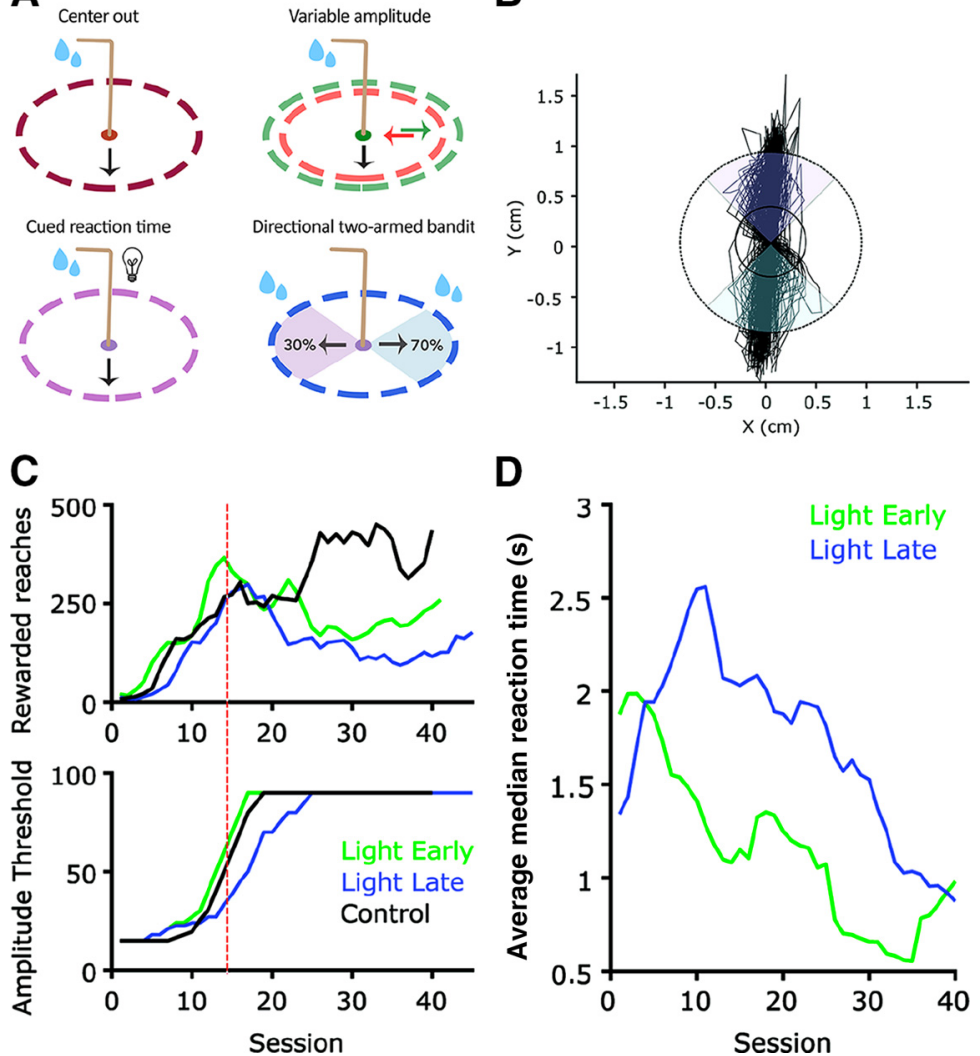

Figure 3. Training and performance of specialized reaching tasks. $\boldsymbol{A}$, The mouse joystick enables (1) a basic center-out task (all directions rewarded, dashed ring = reward amplitude threshold), (2) variable amplitude reaching wherein the reward amplitude can be changed within the session, (3) a reaction time task with a go-cue light, and (4) a bidirectional two-armed bandit task to assess decision-making, among other possibilities. In this case, reaches in different directions carry different reward probabilities. $\boldsymbol{B}$, To demonstrate the ability to make discrete reaches in two directions, we demonstrate an $x-y$ joystick position trace over a 30 min, twoarmed bandit task session wherein the high probability rewarded direction changed with throughout the task. The solid black circle denotes initial training threshold for rewarded reaches at $0.35 \mathrm{~cm}$, and dashed circle representing expert level threshold of $0.9 \mathrm{~cm}$. $\boldsymbol{C}$, Mean number of rewarded reaches (top) and reward threshold amplitude for each session performed by light early (green), light late (blue), and control (black) groups. $\boldsymbol{D}$, Average of median reaction times for each session during light early and light late groups, aligned to cued light introduction session.

accordance with the Carnegie Mellon University animal care committee's regulations.

While the variations on a reaching task are innumerable, several examples that reflect standard experiments common to the non-human primate literature in particular are provided (Fig. 3A). We provide code for the following: (1) basic center-out (direction agnostic) reaching task; (2) variable amplitude operant (VAO) task (Baraduc et al., 2013; Yttri and Dudman, 2018), in which the required threshold for reward is moved throughout the task; (3) reaction time version of the basic task, wherein a light provides a "go" cue; and (4) direction-dependent two-armed bandit task, in which a probabilistic reward contingency must be learned. Reaches in opposing directions carry different reward rates, and these rates change randomly (Fig. 3B).

We have found that it is best to start training on the desired task, rather than the basic task followed by later additions of complexity, hindered later learning of the tasks.

To further test the effectiveness of the joystick platform in conjunction with automated training efficacy, two training paradigms for a reaction time reach task using a light go-cue were tested. The timing of the introduction of the light cue was used as a dependent variable. In the "light early" condition, the go-cue light was introduced on the first day of training. The "light late" condition introduced the go-cue in the seventh session. In both conditions, "punishment" for early reaches (a 5000-ms time out period paired with house lights and restart of trial with new, random ITI) was introduced at day 14 to discourage anticipatory reaches (Fig. $3 C$, dashed red line, two-tailed $t$ test). Two animals (one female, one male) were used in each cue condition. No sex differences were observed $(p>0.6)$. As the $n$ is quite small in this proof of concept documentation, further comparative statistics are of little use. Therefore, error bars have been left out of plots. These data demonstrate that mice can learn the task, and the trends shown may be of use to experimenters. The performance of two control animals (mice performing the basic center-out task with no go-cue) are also shown where appropriate.

All mice were able to learn the task to criterion, defined as performing at least 100 reaches over $0.9 \mathrm{~cm}$ in $30 \mathrm{~min}$. 
Most animals surpassed this standard easily, with the majority performing over 100 reaches by session 7 and all achieving expert level by three weeks ( $>100$ successful reaches over the $0.9-\mathrm{cm}$ amplitude threshold). However, we observed a numerical advantage in the use of the light early over the light late (Fig. $3 \mathrm{C}$ ). The number of trials performed in each of the last four sessions was significant across all conditions (early vs late, $p<0.05$; control vs either condition, $p<0.01$; two-tailed $t$ test). More importantly, we observed that reaction time to the go-cue light reduced more quickly in the light early training regimen (Fig. 3D). We defined reaction time as rewarded movement initiation time minus cue light on time (all reaction times $>5 \mathrm{~s}$ were omitted). A steady decrease in reaction time over training sessions can be observed. Further work must be performed to assess the generalizability of these observations to a larger cohort of animals, but our proof of concept data demonstrate that (1) mice can learn a cuedreaction time reach task and (2) introducing the entire task at once is likely to be preferable to a progressive, piecemeal approach (Kuhlman et al., 2014; Hong et al., 2018).

\section{Discussion}

This work documents an open-source, inexpensive joystick apparatus capable of millisecond and submillimeter resolution and real-time applications. We demonstrate the construction, use, optimization, and offline analysis of the data generated by this modular apparatus. This joystick can be used to study several classic reaching paradigms: a basic center-out reaching task, a cued reaction time version of that task, and a bi-directional, two-armed bandit probabilistic learning task. Perhaps of most use, the described tool setup be used in automated training, thus enabling high-throughput research methods, a critical avenue for the future of neuroscience. While one may glean how to build joystick rigs from other sources (Bollu et al., 2019), we provide the first documentation of a selfcentering joystick with extensive online task code and offline analysis.

In a direct study of the application of this joystick setup, it is demonstrated that mice can reliably learn and reproduce the reaching behavior trained through the designed hardware and software platform. Mice can learn the basic reaching task in two to three weeks. The speed of training is a pronounced advantage over non-human primate studies, which can take months or even years. Although there are some performance attributes that mice are unlikely to ever be capable of, this study (reaction time task, two-armed bandit) and several others continue to narrow the gap between mouse and monkey behavior (Galiñanes et al., 2018; Bari et al., 2019; Stringer et al., 2019).

Looking toward the other end of the spectrum, the implementation of a joystick manipulanum instead of traditional lever-press setups in rodent behavioral work setups seems obvious. Consider pushing a child on a swing or drinking a cup of hot coffee: the manner in which those actions are performed far exceeds the selection of those actions in importance. A reduced, one-dimensional joystick affords fundamental measures of movement speed and amplitude with little to no extra effort. Beyond this, measures like speed and amplitude can be used to assess vigor, motivation, and confidence (Resulaj et al., 2009). These factors are vital in understanding the effects of neural or behavioral perturbations. Learning, not just of what to do but how, is also readily assessed. The compact and modular nature of the setup allows additional task-related devices (e.g., light cue, odor delivery, multiple unimanual joysticks) to be easily integrated into the same experimental setup, thus maximizing the experimental possibilities within one setup.

A limitation with the current design is that animals prefer forward/backward movements rather than left/right movements. It is possible that with some modifications, (differently shaped grip, lower joystick resistance laterally), an animal could move the joystick in all directions equally, opening up greater possibilities for complex tasks. Additionally, while reaches to threshold are consistently trainable and reproducible, mice do learn their own ways of completing the movement, including some that "rev up" (performing a very small reach in the opposite direction before the large reach). Another concern is the tendency for animals to perseverate in tasks reacquiring multiple response directions. This difficulty is common to many tasks with changing demands. To avoid this, we recommend introducing most of the task aspects early in training, and introducing any later changes slowly. For example, introducing punishment timeouts to discourage extraneous reaching after the first week of training to allows mice to better learn, but not give up on, the task before they reach full expert level.

Studying the neural correlates of behavior requires precise, oftentimes real-time measures of those actions. In designing this joystick platform, we have created a low cost and customizable alternative to traditional center out tasks involving non-human primates. The steps to implementation for the hardware, software, online and offline analysis are laid out. This setup takes advantage of the experimental advantages mice offer, including genetic tools and high-throughput automated training-while providing rich spatiotemporal dynamics of motor control, action selection, and decision-making.

\section{References}

Baraduc P, Thobois S, Gan J, Broussolle E, Desmurget M (2013) A common optimization principle for motor execution in healthy subjects and parkinsonian patients. J Neurosci 33:665-677.

Bari BA, Grossman CD, Lubin EE, Rajagopalan AE, Cressy JI, Cohen JY (2019) Stable representations of decision variables for flexible behavior. Neuron 103:922-933.e7.

Bollu T, Whitehead SC, Prasad N, Walker J, Shyamkumar N, Subramaniam R, Kardon B, Cohen I, Goldberg JH (2019) Automated home cage training of mice in a hold-still center-out reach task. J Neurophysiol 121:500-512.

Brunton BW, Botvinick MM, Brody CD (2013) Rats and humans can optimally accumulate evidence for decision-making. Science 340:95-98.

Cherian A, Fernandes HL, Miller LE (2013) Primary motor cortical discharge during force field adaptation reflects muscle-like dynamics. J Neurophysiol 110:768-783.

Churchland MM, Cunningham JP, Kaufman MT, Foster JD, Nuyujukian P, Ryu SI, Shenoy KV (2012) Neural population dynamics during reaching. Nature 487:51-56. 
Cohen JY, Amoroso MW, Uchida N (2015) Serotonergic neurons signal reward and punishment on multiple timescales. Elife 4: e06346.

Dean HL, Hagan MA, Pesaran B (2012) Only coherent spiking in posterior parietal cortex coordinates looking and reaching. Neuron 73:829-841.

Fetsch CR (2016) The importance of task design and behavioral control for understanding the neural basis of cognitive functions. Curr Opin Neurobiol 37:16-22.

Fromm C, Evarts EV (1981) Relation of size and activity of motor cortex pyramidal tract neurons during skilled movements in the monkey. J Neurosci 1:453-460.

Galiñanes GL, Bonardi C, Huber D (2018) Directional reaching for water as a cortex-dependent behavioral framework for mice. Cell Rep 22:2767-2783.

Guo JZ, Graves AR, Guo WW, Zheng J, Lee A, Rodríguez-González J, Li N, Macklin JJ, Phillips JW, Mensh BD, Branson K, Hantman AW (2015) Cortex commands the performance of skilled movement. Elife 4:e10774

Harvey CD, Collman F, Dombeck DA, Tank DW (2009) Intracellular dynamics of hippocampal place cells during virtual navigation. Nature 461:941-946.

Hong YK, Lacefield CO, Rodgers CC, Bruno RM (2018) Sensation, movement and learning in the absence of barrel cortex. Nature 561:542-546.

Kaskan PM, Dean AM, Nicholas MA, Mitz AR, Murray EA (2019) Gustatory responses in macaque monkeys revealed with fMRI: Comments on taste, taste preference, and internal state. Neurolmage 184:932-942.

Klaus A, Martins GJ, Paixao VB, Zhou P, Paninski L, Costa RM (2017) The spatiotemporal organization of the striatum encodes action space. Neuron 95:1171-1180.e7.

Kuhlman SJ, O'Connor DH, Fox K, Svoboda K (2014) Structural plasticity within the barrel cortex during initial phases of whisker-dependent learning. J Neurosci 34:6078-6083.

Lak A, Costa GM, Romberg E, Koulakov AA, Mainen ZF, Kepecs A (2014) Orbitofrontal cortex is required for optimal waiting based on decision confidence. Neuron 84:190-201.

Maeda RS, Cluff T, Gribble PL, Pruszynski JA (2018) Feedforward and feedback control share an internal model of the Arm's dynamics. J Neurosci 38:10505-10514.
Mathis A, Mamidanna P, Cury KM, Abe T, Murthy VN, Mathis MW, Bethge M (2018) DeepLabCut: markerless pose estimation of user-defined body parts with deep learning. Nat Neurosci 21:1281-1289.

Mathis MW, Mathis A, Uchida N (2017) Somatosensory cortex plays an essential role in forelimb motor adaptation in mice. Neuron 93:1493-1503.e6.

Osborne JE, Dudman JT (2014) RIVETS: A mechanical system for in vivo and in vitro electrophysiology and imaging. PLoS One 9: e89007.

Panigrahi B, Martin KA, Li Y, Graves AR, Vollmer A, Olson L, Mensh BD, Karpova AY, Dudman JT (2015) Dopamine is required for the neural representation and control of movement vigor. Cell 162:1418-1430.

Paninski L, Fellows MR, Hatsopoulos NG, Donoghue JP (2004) Spatiotemporal tuning of motor cortical neurons for hand position and velocity. J Neurophysiol 91:515-532.

Resulaj A, Kiani R, Wolpert DM, Shadlen MN (2009) Changes of mind in decision-making. Nature 461:263-266.

Slutzky MW, Jordan LR, Bauman MJ, Miller LE (2010) A new rodent behavioral paradigm for studying forelimb movement. J Neurosci Methods 192:228-232.

Stewart B (2017) Design an Accurate Miniature Joystick. Digi-Key Electronics. Available at https://www.digikey.co.nz/en/articles/ techzone/2017/sep/design-an-accurate-miniature-joystick.

Stringer C, Pachitariu M, Steinmetz N, Carandini M, Harris KD (2019) High-dimensional geometry of population responses in visual cortex. Nature 571:361-365.

Tai LH, Lee AM, Benavidez N, Bonci A, Wilbrecht L (2012) Transient stimulation of distinct subpopulations of striatal neurons mimics changes in action value. Nat Neurosci 15:1281-1289.

Thoroughman KA, Shadmehr R (1999) Electromyographic correlates of learning an internal model of reaching movements. J Neurosci 19:8573-8588.

Yttri EA, Dudman JT (2016) Opponent and bidirectional control of movement velocity in the basal ganglia. Nature 533:402-406.

Yttri EA, Dudman JT (2018) A proposed circuit computation in basal ganglia: history-dependent gain. Mov Disord 33:704-716.

Yttri EA, Liu Y, Snyder LH (2013) Lesions of cortical area LIP affect reach onset only when the reach is accompanied by a saccade, revealing an active eye-hand coordination circuit. Proc Natl Acad Sci USA 110:2371-2376. 